\title{
Effect of ethanol on cell growth, metabolism and cation fluxes in the yeast Metschnikowia reukaufii
}

\author{
HeINZ-UlRich GläSER and Milan HöFER*
}

Botanisches Institut der Universität Bonn, Kirschallee 1, 5300 Bonn, FRG

(Received 4 May 1989; revised 16 January 1990; accepted 13 March 1990)

\begin{abstract}
The yeast Metschnikowia reukaufii could not utilize ethanol as a growth substrate, although ethanol stimulated cellular $\mathrm{O}_{2}$ consumption and the reduction of intracellular nicotinamide adenine nucleotides. Also, ethanol inhibited cell growth in glucose-containing medium. The effect was stronger when the $\mathrm{K}^{+}$concentration in the growth medium was lowered from 5.8 to 0.6 mM. Addition of glucose to an aerated cell suspension caused an initial $\mathrm{H}^{+}$efflux and $\mathrm{K}^{+}$influx in a ratio of approximately $1: 1$. This was followed by a phase of continuing extracellular acidification without any measurable uptake of $\mathrm{K}^{+}$. In contrast, in cells energized by glucose, ethanol stimulated $\mathrm{K}^{+}$efflux; concomitantly, $\mathrm{H}^{+}$extrusion was markedly lowered by ethanol. The rates of $\mathrm{H}^{+}$extrusion correlated with the intracellular level of glucose 6-phosphate and not of ATP. It is concluded that there is a regulatory interaction, though not by a direct effect, between glucose 6-phosphate and the plasma-membrane ATPase. Ethanol appears to activate electron transfer from cytosolic NADH to $\mathrm{O}_{2}$ by a pathway independent of the mitochondrial respiratory chain.
\end{abstract}

\section{Introduction}

Ethanol is produced industrially by anaerobic fermentation of carbohydrates by yeasts or bacteria (Righelato, 1980). The problem in biotechnology is that high concentrations of ethanol kill the cells producing it. Therefore, the inhibitory effect of ethanol on cellular metabolism and growth, especially of the yeast Saccharomyces cerevisiae, has been the subject of considerable research (Leão \& van Uden, 1982; Millar et al., 1982; Ingram \& Buttke, 1984). Under aerobic conditions $S$. cerevisiae can also utilize ethanol as a carbon and energy source (Wasungu \& Simard, 1982) and thus overcome its inhibitory effect on metabolism. This is in contrast to Metschnikowia reukaufii as shown in the present work.

Metabolism supplies the cell with energy to build up an electrochemical proton gradient $\left(\Delta \tilde{\mu}_{\mathrm{H}^{+}}\right)$across the plasma membrane (Eddy, 1978) which, in turn, can be used for active sugar uptake (Aldermann \& Höfer, 1981). As shown in reconstituted plasma-membrane vesicles the plasma-membrane-bound ATPase is the main generator of $\Delta \tilde{\mu}_{\mathrm{H}^{+}}$(Gläser \& Höfer, 1987). Moreover, this $\mathrm{H}^{+}$-pump is stimulated strikingly in the presence of

Abbreviations: FCCP, p-trifluoromethoxyphenylhydrazone; RQ, respiratory quotient.
$\mathrm{K}^{+}$(Gläser \& Höfer, 1986, 1987). Since addition of glucose to yeast suspensions usually causes an increase of active $\mathrm{H}^{+}$extrusion in vivo, it seems very likely that the ATPase can be stimulated also by some metabolic signals. On the other hand, ethanol inhibited the $\mathrm{H}^{+}$ extrusion induced by glucose. Hence, in the present work the effect of ethanol on the energy-supplying system was investigated.

\section{Methods}

Growth conditions. The facultative anaerobic yeast Metschnikowia reukaufii (CBS 5834) was grown in a glucose-containing standard medium as described by Aldermann \& Höfer (1981). After harvesting in the late exponential phase ( $15-17 \mathrm{~h}$ ) and washing in double-distilled water, the cells were aerated for $2 \mathrm{~h}$ before use for the experiments. In growth media with reduced $\mathrm{K}^{+}$concentrations, $\mathrm{K}_{2} \mathrm{HPO}_{4}$ was replaced as appropriate by $\mathrm{Na}_{2} \mathrm{HPO}_{4}$.

Measurements of $\mathrm{pH}$ and of $\mathrm{K}^{+}$concentration. The extracellular $\mathrm{pH}$ was measured by a glass electrode and recorded by an analog digital transformer (Plischke \& Buhr) connected to a Copam PC-401 Turbo personal computer. The intracellular $\mathrm{pH}$ was determined by the distribution of $\left[{ }^{14} \mathrm{C}\right]$ propionic acid $\left(1 \mathrm{mM}, 18.5 \mathrm{GBq} \mathrm{mol}^{-1}\right)$ across the plasma membrane as described by Cartwright et al. (1986), except that the buffer $\mathrm{pH}$ was 4.3. Potassium was measured by atomic absorption spectrophotometry (AAS type 360, Perkin-Elmer) as described by Hauer et al. (1981). 
Determination of intracellular ATP and glucose 6-phosphate concentrations. Cell suspension $(1 \mathrm{ml})$ was mixed with $0 \cdot 1 \mathrm{ml}$ perchloric acid $(6 \mathrm{M})$, frozen, thawed, and neutralized by a buffer containing $1.5 \mathrm{M}$ triethanolamine, $0.1 \mathrm{M}$-acetic acid and $4 \mathrm{M}-\mathrm{KOH}$. The sample was centrifuged and the supernatant $(0 \cdot 1-0.4 \mathrm{ml})$ was added to $2 \mathrm{ml}$ of buffer containing $50 \mathrm{~mm}$-triethanolamine, $\mathrm{pH} 7.5,1 \mathrm{~mm}-\mathrm{MgCl}_{2}$, $20 \mathrm{mM}-\mathrm{KCl}, 0.6 \mathrm{mM}-\mathrm{NAD}^{+}$and $20 \mathrm{~mm}$-glucose. The reaction was started at $20^{\circ} \mathrm{C}$ by the addition of glucose-6-phosphate dehydrogenase ( $5 \mu \mathrm{l}, 1100 \mathrm{U} \mathrm{ml}^{-1}$ ) to measure the glucose 6-phosphate concentration. At the end of the reaction hexokinase $\left(5 \mu \mathrm{l}, 560 \mathrm{U} \mathrm{ml}^{-1}\right)$ was added for the determination of ATP. The stoichiometrically coupled reduction of $\mathrm{NAD}^{+}$was measured as the increase of fluorescence by using a Hitachi fluorescence spectrometer type 650-10 M. The excitation and emission wavelengths were 342 and $460 \mathrm{~nm}$, respectively. The increase of fluorescence was calibrated by defined amounts of both metabolites added successively to the assay.

For the determination of the internal cell volume, which was necessary for the calculation of intracellular $\mathrm{pH}$ and metabolite concentrations, the cell dry weight was measured: $1 \mathrm{mg}$ dry wt corresponded to $2 \mu \mathrm{l}$ intracellular volume as determined by the methods of Rottenberg (1979).

Changes in NADH content. Reduction of nicotinamide adenine nucleotides can be followed in vivo by measuring the increase in cellular fluorescence (Duysens \& Amesz, 1957). The cell suspension $(0.16 \mathrm{mg}$ dry wt $\mathrm{ml}^{-1}$ ) was stirred at $20^{\circ} \mathrm{C}$ in a cuvette of the fluorimeter (see above) to maintain aerobic conditions. The increase in relative fluorescence after addition of a substrate was recorded. In control experiments cells were uncoupled by $0.2 \mathrm{mM}$ FCCP or boiled for $30 \mathrm{~min}$; no fluorescence change by added substrates was observed.

Measurements of cellular $\mathrm{O}_{2}$ consumption and $\mathrm{CO}_{2}$ production. The decrease in $\mathrm{O}_{2}$ concentration in cell suspensions $\left(1.5-2 \mathrm{mg} \mathrm{dry} \mathrm{wt} \mathrm{ml} \mathrm{m}^{-1}\right.$ ) immediately after substrate addition was measured by an oxygensensing electrode (Beckmann). For longer observations and for the determination of $\mathrm{CO}_{2}$ production a conventional Warburg manometer (B. Braun) was used as described by Kleinzeller (1965). For these experiments cells were resuspended (4-6 $\left.\mathrm{mg}^{\text {dry }} \mathrm{wt} \mathrm{ml}^{-1}\right)$ in $0.15 \mathrm{M}$ $\mathrm{KH}_{2} \mathrm{PO}_{4}$ buffer, $\mathrm{pH} 4 \cdot 3$, at $22{ }^{\circ} \mathrm{C}$

Measurements of enzyme activity. The isolation of plasma membranes from $M$. reukaufii and the enzyme assay to determine the plasmamembrane ATPase activity were described by Gläser \& Höfer (1986, 1987). Alcohol dehydrogenase activity was determined in crude extracts after disruption of cells with glass beads (Ballotini). Extract $(0.2 \mathrm{ml})$ was added to $2.2 \mathrm{ml}$ buffer $(\mathrm{pH} 8.7)$ containing $0.4 \mathrm{mg}$ glutathione $\mathrm{ml}^{-1}$ and $0.2 \mathrm{mg} \mathrm{NAD}^{+} \mathrm{ml}^{-1}$. The reaction was started at $20^{\circ} \mathrm{C}$ by addition of $1.5 \mathrm{M}$-ethanol and the increase in absorbance at $366 \mathrm{~nm}$ was measured in an Eppendorf photometer type $1101 \mathrm{M}$.

Chemicals. Diethylstilboestrol, semicarbazide and sodium pyrophosphate were from Sigma; ATP, hexokinase, glucose-6-phosphate dehydrogenase and $\mathrm{NAD}^{+}$were from Boehringer. Orthovanadate was from ICN Pharmaceuticals and FCCP from Fluka. All other chemicals were from Merck. Solutions were made in double-distilled water.

\section{Results}

Growth of $M$. reukaufii on media containing glucose and/or ethanol under aerobic conditions

When cultures were transferred to glucose-containing standard medium, exponential growth continued and the stationary phase was reached after 18-21 h (Fig. 1). However, the cells could not grow on ethanol as sole

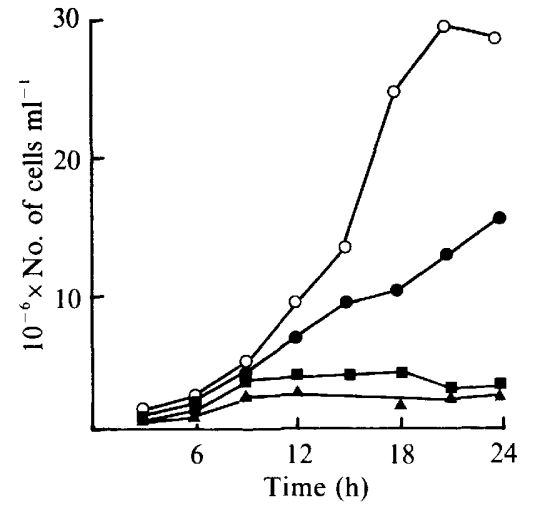

Fig. 1. Effect of ethanol on growth of $M$. reukaufii under aerobic conditions. Growth media: no carbon source $(\square) ; 0.13 \mathrm{M}$-glucose (O); $0.5 \mathrm{M}$-ethanol $(\boldsymbol{\Lambda}) ; 0.13 \mathrm{M}$-glucose $+0.5 \mathrm{M}$-ethanol $(\bigcirc)$.

carbon source (Fig. 1). The generation time of $M$. reukaufii cells in glucose-containing standard medium was increased by ethanol ( $0.5 \mathrm{M}$ ) from 3.3 to $4.5 \mathrm{~h}$ (Fig. 1). Moreover, during growth in the presence of glucose plus ethanol the cell shape changed from elongated to ovoidal (not shown). Although the $\mathrm{K}^{+}$concentration in glucosecontaining standard media was $5.8 \mathrm{~mm}$, a concentration of $0.6 \mathrm{mM}$ was sufficient for maximal growth of $M$. reukaufii. The generation time in medium with a low $\mathrm{K}^{+}$ concentration $(0.6 \mathrm{mM})$ was increased more by ethanol (to $5.7 \mathrm{~h}$ ) than in medium with the standard $\mathrm{K}^{+}$ concentration (see above). This is very likely due to the induction by ethanol of $\mathrm{K}^{+}\left(\right.$and $\mathrm{H}^{+}$) fluxes across the plasma membrane (see Fig. $2 b$ ).

\section{Effect of glucose and ethanol on $\mathrm{H}^{+}$and $\mathrm{K}^{+}$fuxes in aerated cell suspensions}

As observed in several other yeasts, e.g. S. cerevisiae (Eddy, 1978; Sigler et al., 1981), Schizosaccharomyces pombe (Foury et al., 1977) and Rhodotorula glutinis (Höfer \& Misra, 1978), glucose induced a strong acidification of $M$. reukaufi cell suspensions (Fig. $2 a$ ). $\mathrm{CO}_{2}$ production (see Fig. $3 a$ ) contributed to the acidification only to a minor extent, since bubbling $\mathrm{CO}_{2}$ into yeast suspensions increased the $\mathrm{H}^{+}$concentration to only $80 \mu \mathrm{M}$. Diethylstilboestrol $(0.2 \mathrm{~mm})$ and orthovanadate $(0.2 \mathrm{~mm})$, specific inhibitors of the plasma-membrane ATPase (Goffeau \& Slayman, 1981), lowered the initial velocity of glucose-induced acidification by $79 \%$ and $58 \%$, respectively, following $15 \mathrm{~min}$ preincubation (not shown). This inhibition of acidification correlated with the reduction of the ATPase activity of purified plasma membranes, which was inhibited half-maximally by $8 \mu \mathrm{M}$-orthovanadate and $74 \mu \mathrm{M}$-diethylstilboestrol. These results indicate that a stimulation of the plasmamembrane ATPase is mainly responsible for the glucoseinduced acidification. 


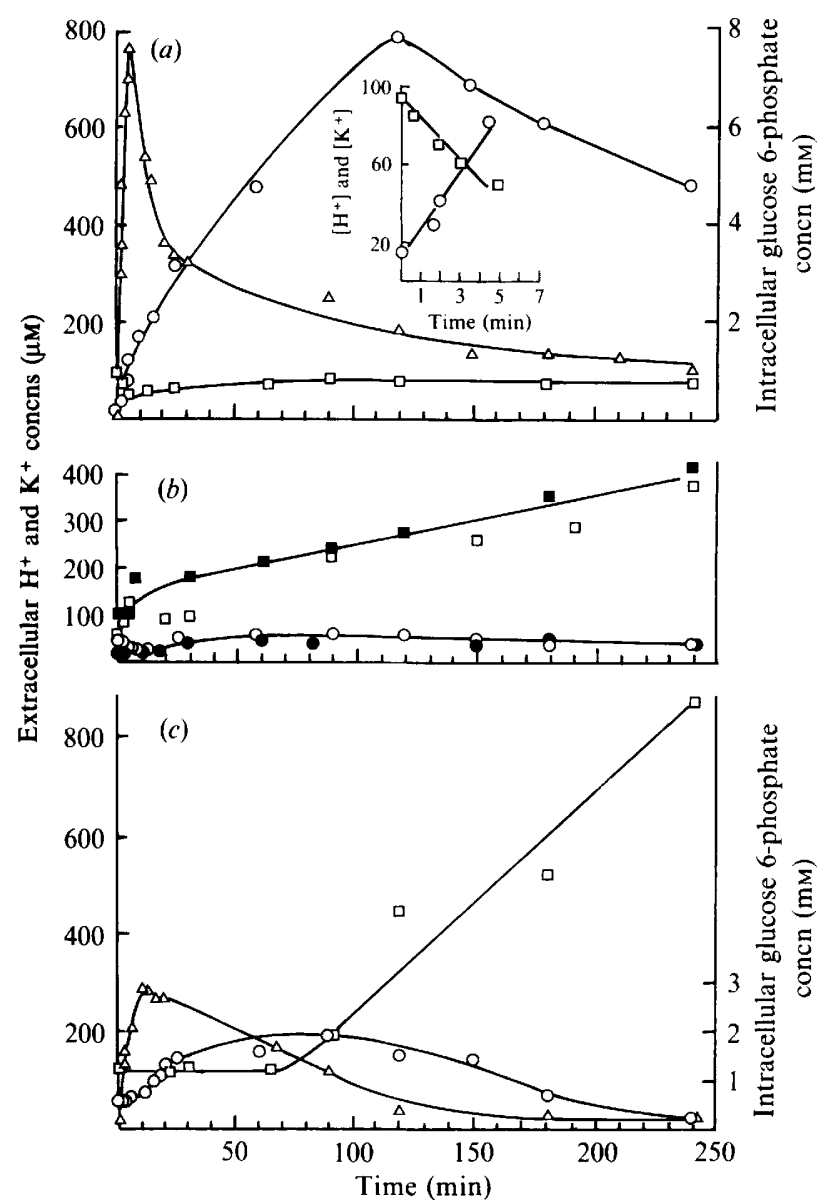

Fig. 2. $\mathrm{H}^{+}(\mathrm{O})$ and $\mathrm{K}^{+}(\square)$ concentrations measured in unbuffered suspensions of $M$. reukaufi following addition (open symbols) at zero time of $(a)$ glucose, $(b)$ ethanol and $(c)$ glucose + ethanol as compared to cell suspensions without added substrate (filled symbols in $b$ ). In addition, the intracellular glucose 6-phosphate concentration $(\triangle)$ was determined. The inset in $(a)$ shows extracellular $\mathrm{H}^{+}(O)$ and $\mathrm{K}^{+}(\square)$ concentration at the start of experiments plotted on an extended timescale. Yeast cells were suspended in double-distilled water (7.3 mg dry wt $\mathrm{ml}^{-1}$ for ion measurements and $10.8 \mathrm{mg}$ dry wt $\mathrm{ml}^{-1}$ for determination of intracellular metabolites). Concentration of added substrates: glucose $(0.02 \mathrm{M})$; ethanol $(0.5 \mathrm{M})$. The results are means of three measurements.

Ethanol $(0.5 \mathrm{M})$ did not induce acidification of $M$. reukaufii suspensions (Fig. $2 b$ ) but strongly inhibited glucose-induced acidification (Fig. $2 c$ ), possibly because the plasma-membrane ATPase is inhibited by ethanol: ATPase activity of purified plasma membranes was inhibited $30 \%$ by $0.5 \mathrm{M}$-ethanol. Another reason for reduced acidification may be the reduced (by up to $40 \%$ ) rate of glucose uptake in the presence of $0.5 \mathrm{M}$-ethanol. However, at the same time respiration was stimulated (see Fig. 3) with virtually no change in cellular ATP level (data not shown).

In aerated suspensions of $M$. reukaufii a steady $\mathrm{K}^{+}$ efflux over a period of $5 \mathrm{~h}$ was observed; this efflux was virtually unchanged in the presence of ethanol (Fig. $2 b$ ). However, release of $\mathrm{K}^{+}$from cells was maximal when glucose was applied together with ethanol (Fig. 2c). In contrast, glucose alone induced a transient uptake of $\mathrm{K}^{+}$ into the cells which was initially stoichiometric with $\mathrm{H}^{+}$ extrusion; the net flux of $\mathrm{K}^{+}$subsequently ceased and the external $\mathrm{K}^{+}$concentration changed only slightly over the next $4 \mathrm{~h}$ (Fig. $2 a$ ). It is evident that ethanol enhanced the permeability of the plasma membrane to $\mathrm{K}^{+}$, particularly in energized cells. A similar stimulation of $\mathrm{K}^{+}$efflux (but without any delay) was observed when glucose was added to cell suspensions preincubated with diethylstilboestrol (results not shown).

\section{Comparison of the effect of glucose and of ethanol on cell metabolism}

The stimulation of $\mathrm{H}^{+}$extrusion by added glucose could not be caused by the enhanced ( $5 \mathrm{mM})$ ATP concentration; the intracellular ATP concentration in resting cells was $4 \mathrm{~mm}$ and hence sufficiently high to permit maximal ATPase activity. The $K_{\mathrm{m}}$ for ATP of the plasmamembrane ATPase is $0.6 \mathrm{~mm}$ (Gläser \& Höfer, 1986).

In contrast, the intracellular concentration of glucose 6-phosphate in $M$. reukaufii first increased after addition of glucose and then decreased after 8 min (Fig. $2 a$ ). The increase was delayed and considerably lessened in the presence of ethanol (Fig. 2c) as expected from the observed decrease in glucose uptake. The rate of $\mathrm{H}^{+}$ extrusion was also delayed and reduced by ethanol $\left(0.8 \mathrm{nmol} \mathrm{ml} l^{-1} \mathrm{~min}^{-1}\right.$ after $6 \mathrm{~min}$ as compared with $17 \mathrm{nmol} \mathrm{ml}^{-1} \mathrm{~min}^{-1}$ in the presence of glucose alone), and correlated well with the increase in glucose 6phosphate concentration. However, the ATPase activity of purified plasma membranes was stimulated by neither glucose nor glucose 6-phosphate. Addition of ethanol alone did not change (not shown) the endogenous glucose 6-phosphate concentration $(<0 \cdot 3 \mathrm{mM})$.

The intracellular $\mathrm{pH}$ of $M$. reukaufii cells also decreased (from 6.64 to 6.40) following addition of glucose. Ethanol did not cause intracellular acidification and did not affect that induced by glucose. The intracellular acidification in the presence of glucose, in spite of the increased $\mathrm{H}^{+}$extrusion, may be explained by glucose catabolism (phosphorylation of glucose, stimulated $\mathrm{CO}_{2}$ production; cf. Figs 2 and 3 ).

Effect of ethanol on cell respiration and on the redox state of nicotinamide adenine nucleotides

$\mathrm{CO}_{2}$ production and $\mathrm{O}_{2}$ consumption by $M$. reukaufi are shown in Fig. $3(a, b) . \mathrm{O}_{2}$ consumption was stimulated by both ethanol $(0.5 \mathrm{M})$ and by glucose $(0.02 \mathrm{M})$ to the same 
extent when measured shortly after their addition (Fig. $3 b$ ). When glucose and ethanol were added together the effect was additive (not shown). Prolonged measurements over a period of $2 \mathrm{~h}$ revealed that the stimulation in $\mathrm{O}_{2}$ consumption induced by ethanol decreased with time, whereas that stimulated by glucose persisted (Fig. $3 b$ ). The non-metabolizable monosaccharide xylose did not stimulate $\mathrm{O}_{2}$ uptake (not shown).

No increase in $\mathrm{CO}_{2}$ production was observed following addition of either ethanol (Fig. 3a) or xylose (the latter not shown). This again indicates that $M$. reukaufi cannot utilize ethanol for growth. However, the intracellular NADH content was increased more by ethanol than by glucose (cf. Fig. $4 b$ and Fig. $4 a$, respectively). Correspondingly, the crude extract exhibited a NAD ${ }^{+}$-

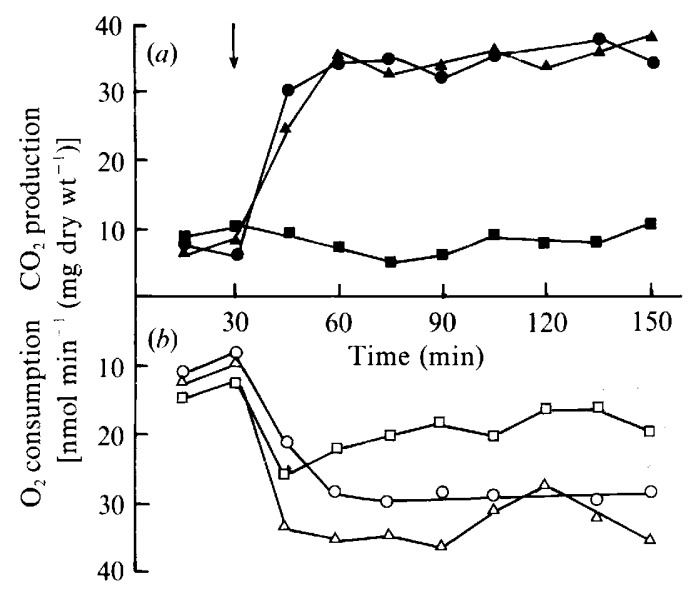

Fig. 3. $\mathrm{CO}_{2}$ production (a) and $\mathrm{O}_{2}$ consumption (b) by $M$. reukaufi cell suspensions after addition (arrowed) of $0.02 \mathrm{M}$-glucose $(\mathrm{O}, \mathrm{O}), 0.02 \mathrm{M}$ glucose $+0.5 \mathrm{M}$-ethanol $(\boldsymbol{\Lambda}, \triangle)$ or $0.5 \mathrm{M}$ ethanol $(\square, \square)$. The results are means of three to six measurements by conventional manometry. dependent alcohol dehydrogenase activity of $0.058 \mathrm{U}$ (mg protein $)^{-1}$. When glucose and ethanol were added together (Fig. 4c) the intracellular NADH content reflected both the characteristic rapid reduction of $\mathrm{NAD}^{+}$by ethanol (cf. Fig. $4 b$ ) and the initial drop followed by a steady increase in NADH content characteristic of glucose catabolism (cf. Fig. 4a). In addition, since respiration and $\mathrm{CO}_{2}$ production from glucose metabolism were not inhibited by ethanol (Fig. $3 a, b)$ interference by ethanol with glucose metabolism can be excluded.

\section{Discussion}

Cells of the yeast $M$. reukaufii could not use ethanol as substrate for growth or for oxidative metabolism producing $\mathrm{CO}_{2}$. In contrast, cells of $S$. cerevisiae can metabolize ethanol either added to the medium (Brown et al., 1981; Wasungu \& Simard, 1982) or produced by the cells under aerobic conditions (Haarasilta \& Oura, 1975; Käppeli, 1986). The minimal $\mathrm{K}^{+}$concentration for uninhibited growth was 0.4 mM (Camacho et al., 1981). Mutants of $S$. cerevisiae have been selected which display similar physiological behaviour to $M$. reukaufi : they cannot grow in media containing ethanol as sole carbon source despite their unchanged glucose catabolism (Aguilera \& Benitez, 1986). It was therefore of interest to investigate in vivo the specific effect of ethanol on cell metabolism and on ion fluxes across the plasma membrane which are driven by metabolic energy.

The extracellular acidification induced by glucose metabolism results from the functioning of the plasma-
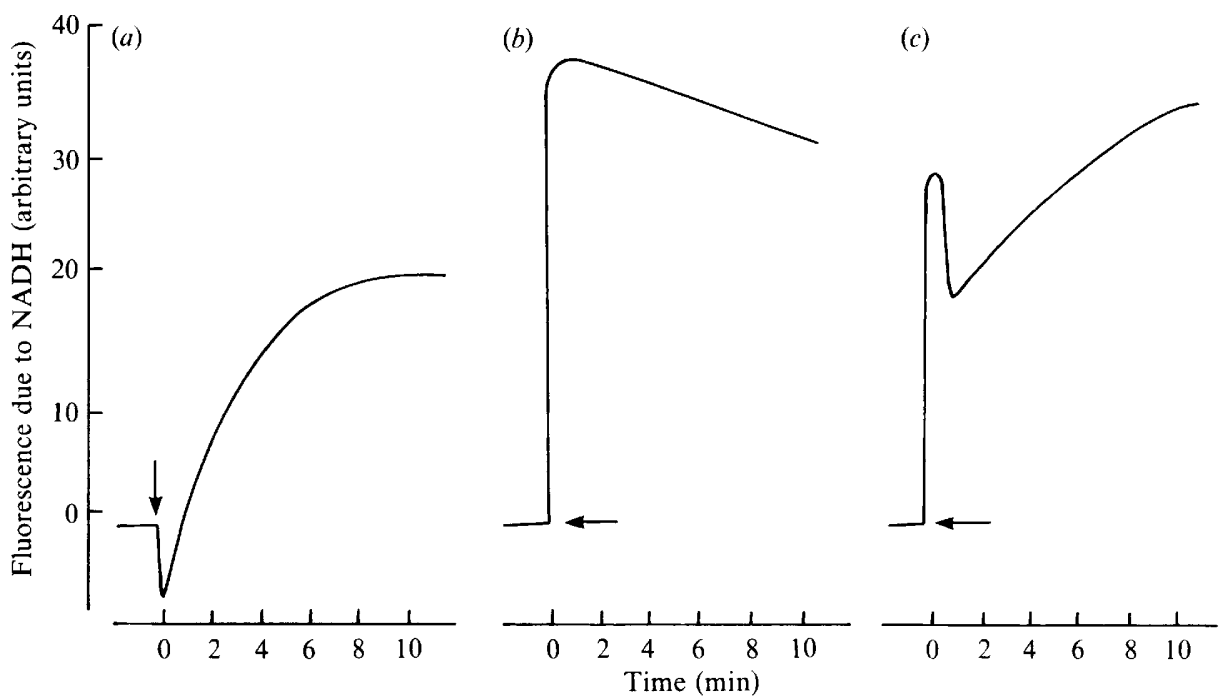

Fig. 4. Changes in intracellular NADH content induced by addition (arrowed) of $0.02 \mathrm{M}$-glucose (a), $0.5 \mathrm{M}$-ethanol (b) or both (c). Cells were suspended in double-distilled water and stirred continuously. The change in fluorescence of NADH was measured at $342 \mathrm{~nm}$ (excitation) and $460 \mathrm{~nm}$ (emission). 
membrane ATPase. This conclusion is based on the correlation of inhibition of the two processes by diethylstilboestrol and by orthovanadate. Moreover, the contribution of $\mathrm{CO}_{2}$ released from glucose metabolism to the decrease in extracellular $\mathrm{pH}$ was negligible in the $\mathrm{pH}$ region below 4.5. The extrusion of $\mathrm{H}^{+}$through the ATPase was initially accompanied by an approximately stoichiometric uptake of $\mathrm{K}^{+}$, which subsequently decreased and then ceased after 5-10 min. The electrical compensation for $\mathrm{H}^{+}$extruded under these conditions is not clear. In $S$. cerevisiae an efflux of organic anions occurs (Pulver \& Verzar, 1940; Rothstein \& Bruce, 1958; Sigler et al., 1981) which could compensate for the charge translocation by the ATPase.

The rate of $\mathrm{H}^{+}$extrusion in $M$. reukaufii was not regulated by intracellular ATP concentration which remained fairly constant (4-5 mM) both in the presence and absence of glucose or ethanol. By contrast, in $S$. cerevisiae the intracellular ATP concentration was, although only transiently (5-15 min), greatly increased in the presence of glucose or ethanol (Rothman \& Cabib, 1969; Maitra \& Estabrook, 1967). However, in $M$. reukaufii the intracellular glucose 6-phosphate concentration appeared to be correlated with the rate of $\mathrm{H}^{+}$ extrusion induced by added glucose, and both were lowered in the presence of ethanol. Hence, glucose 6phosphate appears to be involved in the regulation of $\mathrm{H}^{+}$ extrusion by the plasma-membrane ATPase. However, since neither glucose nor glucose 6-phosphate stimulated the ATPase activity of isolated plasma membranes their intracellular concentrations may act as signals for as-yetunidentified metabolic intermediate(s) involved in regulation of the plasma-membrane ATPase activity. Sychrova \& Kotyk (1985), however, reported an increased ATPase activity in the isolated plasma-membrane fraction from $S$. cerevisiae cells incubated with glucose. A similar observation was made with $M$. reukaufi: the ATPase activity of the plasma-membrane fraction from starved cells (aerated for $2 \mathrm{~h}$ at $30^{\circ} \mathrm{C}$ ) was one-third lower than that of freshly harvested cells grown on glucose (results not shown).

The mechanism of the increased $\mathrm{K}^{+}$efflux from cells incubated with both glucose and ethanol is also unclear. It coincided with a reversal of $\mathrm{H}^{+}$efflux and a drop in respiration. Direct inhibition of glucose catabolism by ethanol can be excluded (except for the decrease in glucose 6-phosphate concentration) since $\mathrm{CO}_{2}$ production in the presence of glucose with and without ethanol was virtually the same. Addition of ethanol alone stimulated cellular respiration without an increase in $\mathrm{CO}_{2}$ production, thus leading to respiratory quotient (RQ) values around $0 \cdot 3$ (the theoretical RQ for ethanol is 0.66). Correspondingly, the intracellular ATP concentration was not increased by added ethanol. In contrast to
$\mathrm{CO}_{2}$ production, $\mathrm{O}_{2}$ consumption appeared to be additive in the presence of glucose plus ethanol. The correlation of early changes in the redox state of cellular nicotinamide adenine nucleotides in the presence of glucose, ethanol or both supports this view. The low RQ values in the presence of ethanol suggest that electrons from ethanol are transferred to $\mathrm{O}_{2}$ via a pathway outside the mitochondria (Crane et al., 1982). This pathway is obviously activated by added ethanol.

Ethanol affects the physiology of $M$. reukaufii cells by indirectly inhibiting the plasma-membrane ATPase. This effect is correlated with changes in intracellular glucose 6-phosphate concentration and increased plasma-membrane permeability to $\mathrm{K}^{+}$(in the presence of glucose). The intracellular glucose 6-phosphate concentration also correlates with the rate of $\mathrm{H}^{+}$extrusion by the ATPase. Hence, a regulatory interaction between this early phosphorylated intermediate of the glucose catabolic pathway and the ATPase function of the plasma membrane has to be postulated. This regulatory mechanism requires further investigation.

This paper is dedicated to Professor Augustin Betz on the occasion of his 70th birthday.

\section{References}

Aguilera, A. \& Benitez, T. (1986). Ethanol-sensitive mutants of Saccharomyces cerevisiae. Archives of Microbiology 143, 337-344.

AldermanN, B. \& HöFER, M. (1981). The active transport of monosaccharides by the yeast Metschnikowia reukaufii: evidence for an electrochemical gradient of $\mathrm{H}^{+}$across the cell membrane. Experimental Mycology 5, 120-132.

Brown, S. W., Oliver, S. G., Harrison, D. E. F. \& Righelato, R. C. (1981). Ethanol inhibition of yeast growth and fermentation: differences in the magnitude and complexity of the effect. European Journal of Applied Microbiology and Biotechnology 11, 151-155.

Camacho, M., Ramos, J. \& Rodriguez-Navarro, A. (1981). Potassium requirements of Saccharomyces cerevisiae. Current Microbiology 6, 295-299.

Cartwright, C. P., Juroszek, J.-R., Beaven, M. J., Ruby, F. M. S., De Morais, S. M. F. \& Rose, A. H. (1986). Ethanol dissipates the proton-motive force across the plasma membrane of Saccharomyces cerevisiae. Journal of General Microbiology 132, 369-377.

Crane, F. L., Roberts, H., Linnane, A. W. \& Low, H. (1982). Transmembrane ferricyanide reduction by cells of the yeast Saccharomyces cerevisiae. Journal of Bioenergetics and Biomembranes 14, 191-205.

DuYsens, L. N. M. \& AmESZ, J. (1957). Fluorescence spectrophotometry of reduced phosphopyridine nucleotide in intact cells in the near-ultraviolet and visible region. Biochimica et Biophysica Acta 24, $19-26$.

EDDY, A. A. (1978). Proton-dependent solution transport in microorganisms. Current Topics in Membranes and Transport 10, 278-360.

Foury, F., Boutry, M. \& GoffEaU, A. (1977). Efflux of potassium induced by Dio-9, a plasma membrane ATPase inhibitor in the yeast Schizosaccharomyces pombe. Journal of Biological Chemistry 252, 4577-4583.

GLÄSER, H.-U. \& HöFER, M. (1986). Effect of cations on the plasmamembrane-bound ATPase from the yeast Metschnikowia reukaufii. Journal of General Microbiology 132, 2615-2620. 
GLäSER, H.-U. \& HöFER, M. (1987). Ion-dependent generation of the electrochemical proton gradient $\Delta \tilde{\mu}_{\mathrm{H}^{+}}$in reconstituted plasma membrane vesicles from the yeast Metschnikowia reukaufi. Biochimica et Biophysica Acta 905, 287-294.

Goffeau, A. \& Slayman, C. W. (1981). The proton-translocating ATPase of the fungal plasma membrane. Biochimica et Biophysica Acta 639, 197-223.

HaARasilta, S. \& OuRA, E. (1975). On the activity and regulation of anapleurotic and gluconeogenic enzymes during the growth phase of baker's yeast. European Journal of Biochemistry 52, 1-7.

Hauer, R., UhlemanN, G., NeummanN, J. \& Höfer, M. (1981). Proton pumps of the plasmalemma of the yeast Rhodotorula gracilis. Their coupling to fluxes of potassium and other ions. Biochimica et Biophysica Acta 649, 680-690.

HöFER, M. \& MiSRA, P. C. (1978). Evidence for a proton/sugar symport in the yeast Rhodotorula gracilis (glutinis). Biochemical Journal 172, $15-22$.

INGRAM, L. O. \& BUTTKE, T. M. (1984). Effects of alcohols on microorganisms. Advances in Microbial Physiology 25, 254-300.

KÄPPELI, O. (1986). Regulation of carbon metabolism in Saccharomyces cerevisiae and related yeasts. Advances in Microbial Physiology 28, 181-209.

KLEINZEllER, A. (1965). Manometrische Methoden. Jena: Gustav Fischer.

LEÃo, C. \& VAN UDEN, N. (1982). Effect of ethanol and other alkanols on the glucose transport system of Saccharomyces cerevisiae. Biotechnology and Bioengineering 24, 2601-2604.

MaITRA, P. K. \& EstabrooK, R. W. (1967). Studies of baker's yeast metabolism. II. The role of adenine nucleotides and inorganic phosphate in the control of respiration during alcohol oxidation. Archives of Biochemistry and Biophysics 121, 129-139.

Millar, D. G., Griffith-Smith, K., Algar, E. \& Scopes, R. K. (1982). Activity and stability of glycolytic enzymes in the presence of ethanol. Biotechnology Letters 4, 601-609.

Pulver, R. \& Verzar, F. (1940). Der Zusammenhang von Kalium und Kohlehydratstoffwechsel bei der Hefe. Helvetica Chimica Acta 23, $1087-1100$.

Righelato, R. C. (1980). Anaerobic fermentation: alcohol production. Philosophical Transactions of the Royal Society B290, 303-312.

RothmaN, L. B. \& CABIB, E. (1969). The efflux of potassium from yeast cells into a potassium free medium. Biochemistry 8, 3332-3341.

RothSTEIN, A.\& BRUCE, M. (1958). Regulation of glycogen synthesis in the intact yeast cell. Journal of Cellular and Comparative Physiology 51, 439-455.

ROTTENBERG, H. (1979). The measurements of membrane potential and $\Delta \mathrm{pH}$ in cells, organelles, and vesicles. Methods in Enzymology 55 , $547-549$.

Sigler, K., Kotyk, A., Knotkova, A. \& Operakova, M. (1981). Processes involved in the creation of buffering capacity and in substrate-induced proton extrusion in the yeast Saccharomyces cerevisiae. Biochimica et Biophysica Acta 643, 583-592.

SYCHROVA, H. \& KoTYK, A. (1985). Conditions of activation of yeast plasma membrane ATPase. FEBS Letters 183, 21-24.

WASUNGU, K. M. \& SimARD, R. E. (1982). Growth characteristics of baker's yeast in ethanol. Biotechnology and Bioengineering 24, 11251134. 